\title{
Role of spinal anesthesia in the endoscopic treatment of distal, middle, and proximal ureter stones
}

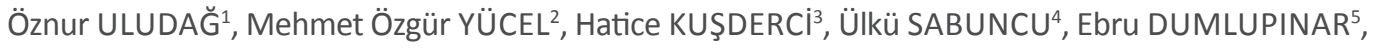
Ruslan ABDULLAYEV ${ }^{1}$

\footnotetext{
${ }^{1}$ Department of Anesthesiology and Reanimation, Adıyaman University Medical School, Adiyaman, Turkey.

${ }^{2}$ Department of Urology, Adiyaman University Medical School, Adıyaman, Turkey.

${ }^{3}$ Anesthesiology and Reanimation Clinic, Bandırma State Hospital, Balikesir, Turkey.

${ }^{4}$ Department of Anesthesiology and Reanimation, Tepecik Research And Educational Hospital, İzmir, Turkey.

${ }^{5}$ Department of Biostatistics and Medical Informatics, Adıyaman University Medical School, Adiyaman, Turkey.
}

\section{SUMMARY}

Sympathetic fibers of the ureter arise between 10th thoracic and 2nd lumbar segments. Nociceptive fibers reach the same segments via sympathetic pathways. An effective neural block of these segments is necessary to achieve adequate analgesia and anesthesia. Spinal anesthesia is performed successfully in endoscopic ureter stone operations as an alternative to general or epidural anesthesia with a fast onset of effect. The aim of this study was to evaluate patients who underwent ureterorenoscopy (URS) under spinal anesthesia so as to determine patient profile and anesthesia management according to the localization of stones.

Patients who underwent URS operation due to urinary stones between January 1, 2014, and December 31, 2014, were retrospectively evaluated. Patients who underwent spinal anesthesia were included. The patients were evaluated for demographic data, duration of operation, duration of hospital stay, and size and localization of stones.

A total of 111 patients, including 84 males (75.5\%), were operated under spinal anesthesia. A significant sex-related difference was noted, with more ureter stones in male patients $(P=0.001)$. No difference was found in operation time, duration of hospitalization, and stone size among stones at different localizations of the ureter under spinal anesthesia.

No difference was found in stone localization, duration of operation, duration of hospital stay, and stone size between distal, middle, and proximally located stones under spinal anesthesia. Spinal anesthesia may be chosen for the management of anesthesia in treating stones located at all three locations of the ureter:

Key words: Spinal anesthesia, ureterorenoscopy, ureterstone

\section{INTRODUCTION}

The aim of surgical interventions in urinary system stone disease is to remove stones with minimal morbidity. Currently, ureterorenoscopy (URS) is commonly used for the treatment of ureter stones with rapid developments in the technology of endoscopic tools and devices. URS is the first-choice treatment for distal ureteric stones of size $\geq 10 \mathrm{~mm}$; it has been used successfully for all ureteric stones (1). Although the most effective lithotripsy system is Ho:YAG laser lithotripsy, pneumatic and ultrasonic lithotripsy may also effectively fragment stones (2)

Sympathetic fibers of the ureter arise from 10th thoracic to 2 nd lumbar segments. They synapse with postganglionic fibers at the aorticorenal, inferior, and superior hypogastric plexuses. Its parasympathetic innervation originates from the second and third sacral spinal segments. Nociceptive fibers reach spinal segments together with sympathetic fibers (3). Effective neural blockage of these segments is necessary to achieve adequate analgesia and anesthesia.

Spinal anesthesia can be used successfully in URS operations as an alternative to general anesthesia due to its rapid onset of action. Although spinal anesthesia is widely used for treating lower and middle ureteric stones, general anesthesia is preferred for upper ureteric stones because patient movements are controlled and stone movements due to respiration can be eliminated by adjusting ventilator parameters. A disadvantage of spinal anesthesia is the difficulty in positioning

Correspondence:

Mehmet Özgür YÜCEL

Adıyaman Üniversitesi, Tıp Fakültesi, Üroloji Bölümü, Adıyaman, Türkiye.

e-mail: mozyucel@yahoo.com 
if the patient needs additional procedures. Spinal anesthesia has many advantages over general anesthesia, such as patient being awake, absence of the loss of protective reflexes, maintenance of spontaneous respiration, early mobilization after the operation, lesser duration of hospitalization, lower rate of positional, pulmonary, vascular, or neurological complications, and decreased treatment cost (4).

The aim of this study was to evaluate patient profile and anesthesia management in patients who underwent URS with spinal anesthesia, so as to prove that URS could be performed effectively under spinal anesthesia for upper ureteric stones.

\section{MATERIAL AND METHODS}

After approval from the Ethics Committee of Adiyaman University Medical School (date: 29.01.2015; no: 57831858/5), the charts of patients who underwent URS between January 1, 2014, and December 31, 2014, were retrospectively evaluated. Patients operated under spinal anesthesia were included in this study. The images of the patients were evaluated. Stones below the lower margin of the sacroiliac junction were defined as lower ureteric stones, stones at the level of the sacroiliac junction were defined as middle ureteric stones, and stones above the upper margin of the junction were defined as upper ureteric stones. The patients were divided into three groups according to the stone level. The demographic features of the patients, duration of operation, duration of hospitalization, size and localization of the stones, and duration of surgery were compared.

The SPSS 21.0 package program was used for statistical analysis. The chi-square test was used for comparing sex-related data. Age, duration of operation and hospitalization, and size and localization of stones were compared using the independentsamples $t$ test. Pearson correlation was used for evaluating the duration of operation. A Pvalue $<0.05$ was considered statistically significant.

\section{RESULTS}

A total of 111 patients (84 (75.5\%) males and 27 (24.5\%) females) underwent URS operations under spinal anesthesia. A significant sex-related difference was noted, with males having more ureteric stones $(P=0.001)$. No difference in age, duration of operation, duration of hospitalization, or stone size was found between male and female patients (Table 1).

No relation was found between duration of hospitalization or operation, stone size, and age (Table 2).

TABLE 1: Demographic characteristics of the patients, operation and hospitalization durations, and ureteral stone sizes.

\begin{tabular}{llll}
\hline & Male & Female & $P$ value \\
\hline Number of patients & $84(75.5 \%)$ & $27(24.5 \%)$ & $0.001^{*}$ \\
Age (year) & $40.89 \pm 14.56$ & $37,85 \pm 16,70$ & 0.365 \\
Operation duration (min) & $46.98 \pm 11.23$ & $48.48 \pm 7.53$ & 0.517 \\
Hospitalization duration (day) & $2,81 \pm 1,83$ & $3.04 \pm 3.58$ & 0.666 \\
Stone size $(\mathrm{mm})$ & $7,47 \pm 1,95$ & $6.78 \pm 2.35$ & 0.133 \\
\hline
\end{tabular}

Variables except patient number are given as mean \pm standard deviation (SD). $\quad * p<0.001$.

TABLE 2: Correlations between duration of hospitalization or operation, stone size, and age.

\begin{tabular}{lll}
\hline & $\begin{array}{l}\text { Correlation coefficient with duration of } \\
\text { hospitalization }\end{array}$ & $P$ value \\
\hline Stone size $(\mathrm{mm})$ & 0.098 & 0.306 \\
Duration of operation $(\mathrm{min})$ & 0.096 & 0.316 \\
Age (year) & 0.008 & 0.937 \\
\hline
\end{tabular}




\begin{tabular}{|c|c|c|c|c|}
\hline Localization of ureteral stones & Distal & Middle & Proximal & $P$ value \\
\hline Sex: Male & $58(82.9)$ & $12(63.2)$ & 13 (61.9) & 0.077 \\
\hline Female & $12(17.1)$ & 7 (36.8) & $8(38.1)$ & \\
\hline Age (year) & $41.64 \pm 15.44$ & $34.47 \pm 10.84$ & $39.47 \pm 16.4$ & 0.182 \\
\hline Operation duration (min) & $47.684 \pm 10.91$ & $48.52 \pm 8.18$ & $45.14 \pm 11.03$ & 0.547 \\
\hline Hospitalization duration (day) & $2.92 \pm 2.54$ & $3.10 \pm 2.6$ & $2.47 \pm 1.4$ & 0.672 \\
\hline Stone size $(\mathrm{mm})$ & $7.35 \pm 2.05$ & $6.84 \pm 2.31$ & $7.52 \pm 1.96$ & 0.547 \\
\hline
\end{tabular}

\begin{tabular}{|c|c|c|c|c|c|c|c|c|}
\hline & Right lower & Left lower & Right middle & Left middle & Right upper & Left upper & $P$ & \\
\hline \multirow{4}{*}{ Sex } & Male & 27 & 32 & 4 & 8 & 6 & 7 & 0,06 \\
\hline & & (90\%) & (77.5\%) & (44.4\%) & $(80 \%)$ & $(66.7 \%)$ & (58.3\%) & \\
\hline & Female & 3 & 9 & 5 & 2 & 3 & 5 & \\
\hline & & $(10 \%)$ & $(22.5 \%)$ & (55.6\%) & $(20 \%)$ & (33.3\%) & (41.7\%) & \\
\hline
\end{tabular}

Stone location was not significantly different between sexes ( $P=$ 0.07). No significant difference was found in the localization of the stone, age, duration of surgery, duration of hospitalization, or stone size (Table 3).

The localization of ureteric stones in male and female patients is presented in Table 4. No difference was found between sexes $(P=0.06)$.

An adequate level of anesthesia was achieved in all patients, and general anesthesia was not needed in any patient. No complication was observed in the patients. Mean $( \pm)$ duration of hospital stay for male and female patients was $2.81 \pm 1.83$ days and $3.04 \pm 3.58$, respectively.

\section{DISCUSSION}

URS is a reliable and easy procedure commonly used to treat ureter stones. The stone size and duration of operation and hospitalization were not different in 111 patients who underwent URS for upper ureteric stones under spinal anesthesia in this study. Motor and sensory block achieved by spinal anesthesia provided sufficient anesthesia during the operation. No complication developed in the patients. Maghsouidi et al compared the lithotripsy methods used for treating ureteral stones. They found that the incidence of urethral stones was higher in males (6). The incidence of ureteral stones in the present study was also found to be high in male patients.

A study reported that general anesthesia providing muscle paralysis is usually preferred in URS procedures to avoid ureteral injuries due to movement of the patients (5). Another study showed that the epidural procedure was successful (7). Some other studies also reported that epidural anesthesia, intravenous sedation combined with local anesthesia, and only local anesthesia were safe anesthesia methods for URS procedures $(8,9,10)$.

A study compared general and spinal anesthesia for URS procedures according to the duration of operation and hospitalization and complications. It found that spinal anesthesia decreased the duration of operation and hospitalization, and did not cause additional risk in general anesthesia. Further, it increased patient satisfaction and minimized postoperative pain, thus serving as a safe method (11).

A study evaluated postoperative complications due to anesthesia and found that the rate of complications due to general anesthesia was higher than that due to central regional anesthesia. The 
duration of anesthesia was longer in patients who underwent general anesthesia than in those who underwent central regional anesthesia. General anesthesia was reported to have several disadvantages such as airway compromise, increased postoperative complications due to gastric regurgitation and pulmonary aspiration, increased postoperative nausea, vomiting, and pain, and increased morbidity and mortality due to these factors. The most important factors for selecting regional anesthesia techniques were the absence of postoperative respiratory complications, easier control of early and late postoperative pain, low cost, and earlier discharge from hospital (12).

A study evaluated intraoperative and postoperative complications, visual analog scale, and duration of hospitalization in 75 male and 50 female patients who underwent URS and in situ lithotripsy for upper ureteric stones under spinal anesthesia. It reported that spinal anesthesia could be safely used for treating upper ureteric stones (13). Khurshid et al reported that postoperative somnolence and risk of pulmonary aspiration were lower in patients who underwent spinal anesthesia because the patients were awake.

A study compared general anesthesia and spinal-epidural anesthesia in patients who were planned to have retrograde intrarenal surgery for minimally invasive stone treatment. It found that the duration of operation and stone breakdown, pain score 6 and $24 \mathrm{~h}$ after surgery, incidence of complications, stone-free rate, and duration of hospitalization were similar between groups. The treatment cost was lower in patients who underwent spinalepidural anesthesia. The study reported that spinal anesthesia could be used as an alternative to general anesthesia (14).

The most important limitations of the present study were its retrospective nature and dependence on anesthesia records.

In conclusion, this study showed that spinal anesthesia was a safe and preferred method for endoscopic treatment of ureteric stones located at all three locations of the ureter because it did not cause postoperative respiratory complications. Also, it had advantages such as early discharge from hospital and low cost. Further studies are recommended in this field.

\section{REFERENCES}

1. Preminger GM, Tiselius HG, Assimos DG, et al. 2007 guidelinefor the management of ureteralcalculi. J Urol 2007;178:2418-34.

2. Aridogan A, Zeren S, Bayazit Y. Complications of pneumatic ureterolithotripsy in the early postoperative period. J Endourol. 2005;19:50-3

3. Cybulski PA, Joo $H$, John R D'A. Ureteroscopy: anesthetic considerations. Urol Clin of N Am 2004; 31 (1): 43-47

4. Morgan GE, Maged SM. Clinical Anesthesiology. Second Edition. Los Angeles: Appleton-Lange, 1996.

5. Harmon WJ, Sershon PD, Blute ML, Patterson DE, Sequra JW. Ureteroscopy: currentpractice and long-termcomplications. J Urol 1997; 157: 28-32.

6. Maghsoudi R, Amjadi M, Norizadeh D, Hassanzadeh H. Treatment of ureteral stones: A prospective randomized controlled trial on comparison of Ho:YAG laser and pneumatic lithotripsy. Indian $J$ Urol 2008; 24(3): 352-354. doi: 10.4103/0970-1591.39549

7. NettoJunior NR, ClaroJde A, Esteves SC, Andrade EF. Ureteroscopics tone removal in the distalureter. Whychange? J Urol 1997; 157: 2081-3.

8. Wills TE, Burns JR. Ureteroscopy: an outpatientprocedure? J Urol 1994; 151: 1185-1187.

9. Rittenberg $\mathrm{MH}$, Ellis DJ, Bagely $\mathrm{DH}$. Ureteroscopy under local anaesthesia. Urology 1987; 30: 475-478.

10. Vogelli A, Mellin HE, Hopf B, Ackermann R. Ureteroscopy under local anaesthesia with and without intravenous analgesia. Br J Urol 1993; 72: 161-164.

11. Shaikh AH, Khalid SE, Zaidi SZ. Ureteroscopy Under Spinal Versus General Anaesthesia: Morbidity and Stone Clearance. J Coll Physicians Surg Pak, 2008; 18(3): 168-171.

12. Yavaşcaoğlu B, Kaya FN, Özcan B, Uzunalioğlu S, Güven T, Yazıcı, G Ocakoğlu Ş. Erişkinlerde Anestezi Sonrası Görülen Komplikasyonların Retrospektif Değerlendirilmesi. Uludağ Üniversitesi Tıp Fakültesi Dergisi 2009; 35 (2) 73-78.

13. Khurshid WCH, Sajid MA, Ahmed M, Fayaz FRM. Spinal anesthesia for ureterorenoscopy and in situlithotripsy for upper ureteric solitary pelvic calculi - an experience at POF hospital. Rawal Med J 2009; 34(2): 210-212.

14. Guohua Z, Zhijian Z, Fengquan Y, Wen Z, Wenqi W, Wenzhong C. Retrograde Intrarenal Surgery with Combined Spinal-Epidural vs General Anesthesia: A Prospective Randomized Controlled Trial. Journal of Endourology. 2015; 29(4): 401-405. doi:10.1089/ end.2014.0249. 